\title{
From Theory to Practice: A Language and Literacy in Workshop for Immigrant Students' Parents Light of Continuing Education
}

\author{
من النظرية للتطبيق: ورشة عمل تعليم القراءة والكتابة لأولياء أمور الطلبة \\ المهاجرين في ضوء التعليم المستمر
}

Alhasef By: Moonerah Mesfer

الباحثة/ منيرة بنت مسفر الحصف

\begin{abstract}
This workshop aims to plan and organize a number of components of the Interactive Model of Program Planning, described by Caffarella and Daffron (2013) in Planning Programs for Adult Learners. For each component, I will explain the activities included in that component, the importance of that component to design my program and how I carried them out in the process of planning the training program. Finally, this paper concluded with several appendices that include a summative reflection of learners and instructor's evaluation, and also learning objectives and activities to meet the objectives.

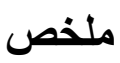

تهذف هذه الورشة لتخطيط وتنظيم عدد من خطوات النموذج التفاعلي لتخطيط

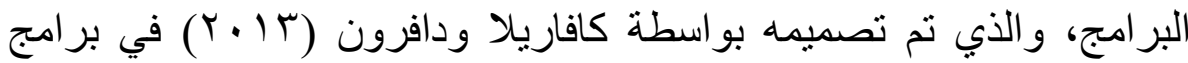

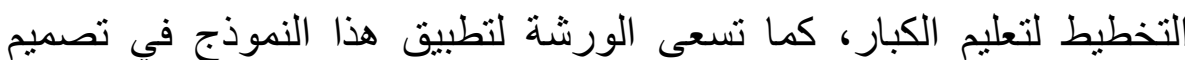

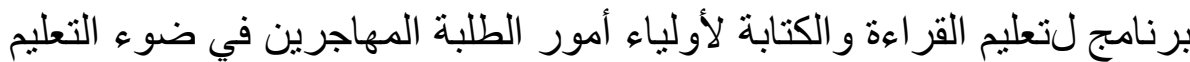

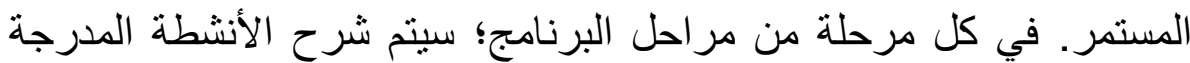
فيها، وأهمية هذه المراحل في تصميم البرنامج، وكيف تم تتفيذه في عملية

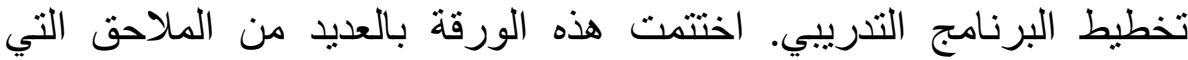
تتضمن تقييماً موجزًا للمتعلمين الكبار و المعلمين، وكذلك أنشطة التعلم الساعية

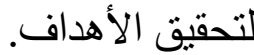




\section{Introduction}

"In the US, A long-awaited federal study finds that an estimated 32 million adults in the US- about one in seven - are saddled with such low literacy levels that it would be taught for them to read anything more challenging than a children's picture book or to understand a medications side effects listed on a pill bottle. Training parents to teach their children reading with specific exercises produced greater results than having parents to listen to their child read without training. Due to considerable variability of the studies within the three intervention types, results must be interpreted with caution".

(Darling \& Westbury, 2004, pp. 775)

The above statement emphasizes the importance of programs that have significant success in training parents to support their children's literacy outcomes, in enhancing students' development to read and write, and in lowering the anxiety parents have felt while helping their children's to read and write. However, there is a little considerable attention on programs caring for families from low socio-economic backgrounds or ESL families. In practice, it is helpful when planning future programs that promote early literacy for immigrant parents to help their kids in reading and writing.

Program planning is being studied throughout many planning models. Those models are all guided by (power, interests, and negotiation) question-based approaches (Sork, 2010). However, the planning process should include clear defined goals for content, an evaluation of the program, and instructional support for the facilitator. In this final project for the program-planning course, I am developing a three-day workshop with concentration on the assumptions of power, interests, needs and cultural differences in order to train non-English speaker immigrant parents to support their child's learning and development in literacy. In fact, the concept of power dynamics is one aspect of our course topics, which I will seriously consider the most important while I plan my workshop. Anderson and 
Morrison (1999-2000) developed the Parents As Literacy Supporters (PALS) program in collaboration with other educators and members of the community (Anderson \& Morrison, 2007). Nevertheless there remain some important questions "What about if parents are still English language learners?" Do they have the ability to support their kids' literacy? Does the program that help parents improve their children's reading skills also improve parents' own literacy? In fact, since immigrant parents are still English language learners, my workshop will not to teach them how to learn the language. My workshop aims to help parents support their children's literacy development and therefore enhance their own English language learning while working with their kids.

The workshop plan is organized following a number of components of the Interactive Model of Program Planning, described by Caffarella and Daffron (2013) in Planning Programs for Adult Learners.

\section{I- Discerning the Context}

Caffarella \& Daffron (2013) suggest that the educator's make related to their program can be affected by "human, organizational, and wider environmental factors in regards to program planning and evaluation" (p. 80). Educators are encouraged to gain enough understanding of these three factors, that known as the context.

The People: We all know that any training program is going to involve people since "Theories do not plan programs-people do" (Forester, 1989). Involving people is necessary while designing programs because people "plan programs in organizations, which have traditions, political relationships and needs and interests that influence the planning process" (Cervero \& Wilson, 1996, p. 7). This literacy program involves me, as the trainer and the facilitator and also involves learners (trainees). These people are new comers to Canada; immigrants and refugees parents who will be asked to work with their school kids. They are drawn from our

$$
-\varepsilon T \vee-
$$


community and from different countries, as a result, they have different cultural expectations and language expertise. They have different budgets to draw on, and differing levels of educational experience. Finally, there are three supervisors interested in the program to observe learners and follow the program progress as will as the manager who I consult during the program applying period.

The organization: Caffarella \& Daffron (2013) divide the context of any organization for program planning into cultural, structural, and political factors. Structurally and politically, the members are immigrants and new comers to Canada from different places. My organization's culture differs based on their original countries. Parents are invited to workshops that focus on the strengths of their culture and the importance of respecting other cultures. I completely agree with Caffarella \& Daffron when they assure that program planners should be sensitive to cultural, language, ethnicity and religious differences (2013). I will use the parent's own cultural values to negotiate and encourage them to get involved in the organization. In this way, I could use the positive power dynamics and interests to influence my participants.

The wider environment: The environmental context involves the political, economic, and social climate of the program place. Some immigrant families are lacking in empowerment on literacy. They live in Canada for years as illiterates since their illiteracy is demonstrated in their inability to find jobs to support their families.

Each member of those people has his/her own needs for the program. Some immigrant families are lacking in empowerment and guidance on literacy. They come to Canada in search of a better life for their children. Immigrant and refugee families care greatly about education and have high aspirations for their children. However, parents from socially, linguistically, and politically marginalized groups fail to achieve at the same rates of development as those from mainstream communities (Kaestle, et al., 1991). The purpose of developing this literacy program is to integrate authentic literacy activities with the main goal of raising low-English literacy levels of the parents and the English emergent literacy levels of their kids. Before

$$
-\varepsilon \uparrow 1-
$$


starting the program, it is significant to listen to the member's voices and negotiate with them to know their needs and therefore to establish a successful program. Because I realize who I am planning the program for, I am prepared to address their issues of power, negotiation, cultural differences, and ethics in order to meet the program planning objectives effectively. Finally, I need to find the chance to discuss the program with supervisors of literacy to gather their feedback and I have to consult other experts of adult education.

\section{II- Building a Solid Base of Support}

Caffarella \& Daffron (2013) emphasize the significance and need of having program support from individual stakeholders, internal support from organizations, and external support from community. In my program planning, I have a support through discussions and interviews with some potential learners, supervisors of potential participants, management of the sponsoring organization, and other stakeholders who have an interest in the results of the program. I will try to gain at least their initial commitment and evaluation to investigate the program once it is available. My initial focus is to ascertain the willingness and needs of parents to follow their kids' literacy and to compile a set of recommendations for developing a family literacy project. When I finish designing the program, I will invite some parents (stakeholders) to give their initial feedback that meets their needs and expectations. I intend to consult different trainees from different places and cultures to ensure a more widely applicable evaluation of the initial family literacy program design. The participants' feedback, discussions and evaluation will be continuing during the period of program application in order to be effective and meeting their needs. Furthermore, supervisors' support is very important to gain the program success. They will be asked to help and guide the trainees how to apply the correct steps and instructions during the program period and then give their feedback and comments to be taken into considerations.

My own manager is a supervisor who gave strong organizational commitments to the designed program. He expressed his concern about the need for this training program due to the growing of immigrants' population in Canada and the need to meet the demands of this population

$$
-\leq 79-
$$


being addressed.

Finally, the community support is another significant factor in applying the program successfully. There will be an ongoing communication with the community to share the others' experience in order to ensure that the program continues to develop in ways that are relevant to these external community organizations. Community centers and schools involved in this project are collaborative and supportive. I will build sustainable collaborative partnerships with other organizations and groups interested in the family literacy programs such as The Centre for Family Literacy Association.

The need for parents' literacy training seems to be clear and a solid base of support for the delivery of this training seems to be abundant and encouraging.

\section{III- Identifying and Prioritizing Program Ideas and Needs}

"The need to identify and prioritize relevant program ideas and needs is one of the major tasks of people involved with planning education and training programs" (Caffarella \& Daffron, 2013, p.134). Two major factors have to be considered in developing an educational program; understanding the needs and prioritizing ideas.

- Identifying ideas and needs:

Gathering ideas for programs can come from a wide range of techniques of needs assessment. According to Caffarella \& Daffron (2013) Ideas can be gained from some different sources as personal observations, people, organizations, communities and society (p.136). The needs assessment is required before any training program can be developed and implemented (Neitzel, 2006). We learned in our program planning course that it is crucial to recognize why learners or trainees must be properly trained, and then to determine what the specific needs are. In the process of planning for my workshop program, the idea for developing literacy workshop for English learner parents grew out of observations, discussions and interviews with some immigrants that need such a course. I used paper and computer-

$$
-\varepsilon \vee \cdot-
$$


based surveys to obtain feedback from parents and a paper survey to receive feedback from educational faculty regarding particular program characteristics. The idea was then developed by my instructor, who helped me in designing and improving the program ideas and plans. Also, I gathered some information about family literacy from the organization of The Centre for Family Literacy that has the goal of matching tutors with adults who needed to help their kids to develop reading, writing and math skills. According to Caffarella \& Daffron, one of the most important outcomes of a highly structured needs assessment may be a commitment by those involved in the process to ensure that the ideas from the needs assessment are actually used in the program planning process (2013). The findings from the parents', organizations' and community's surveys assure that many immigrant families have a strong desire for their children to be successful in school. Those parents are willing, and want to help in the literacy development of their children. However, most of them are unsure of how to teach reading and writing or help their children with literacy since they are still English language learners. - Prioritizing Ideas:

After identifying ideas and needs for the program, it is necessary to define priority ideas. "Priority" in program planning means having an earlier or antecedent claim to resources (Sork, 1998). There were two steps that I followed when prioritizing the ideas. First, I sorted out which ideas that should be solved with the developed training program and which would be better solved by an alternative intervention. Then I prioritized the remaining ideas by determining which ones are most important and feasible. In fact, I struggled to decide if my training program should be developed or an alternative intervention chosen. However, I took the advice of Caffarella \& Daffron when they stated that designing alternative intervention needs to be highly structured and could be affected by people, organizational and environmental factors and cost (2013). Therefore, I chose to develop a literacy workshop program for immigrants. 


\section{IV- Developing Program Goals and Objectives}

Determining goals and objectives of any program is necessary since a planner should consider the learning outcomes that the participants will achieve as a result of the training, and the adaptability of the content toward this end. According to Caffarella \& Daffron (2013) "objectives are clear statements of the anticipated results to be achieved through an educational and training program" (p. 174). They state, "they serve as the foundation for instructional plans, transfer of learning, and evaluations" (Caffarella \& Daffron, 2013, p.175). They divide them into participant objectives and organization objectives, and within both of these, there should be measurable and non-measurable outcomes included. Goals, on the other hand, "are typically broad statements of purpose or intent for the program" (Caffarella \& Daffron, 2013, p. 174). When developing my literacy workshop program, both objectives and goals are measurable and nonmeasurable and also directive in nature. My objectives are clearly written so that all members involved understand them and can negotiate changes if necessary. They may also result in unanticipated outcomes and are flexible enough to change over time.

The parents' literacy training program goals and objectives:

Measurable goal: To allow all learners to be able to help in the literacy development of their children within 3 days.

Non-measurable goal: To help all learners with all their ethnic backgrounds and cultures to become more comfortable, welcomed, respected doing the training.

A- participants' objectives are:

\section{-To help parents support their children's literacy development.}


-To help parents improve their own English literacy when sharing their kids' schoolwork.

-To practice ideas for some simple activities that parents can do at home with their children.

-To learn techniques in order to share their culture with their children, such as storytelling or talking about the significance of certain foods and mealtime in their home country.

B- Organization Objectives are:

Measurable

-To increase community volunteer contributions to the project (training, translations, support forum participation, etc.) by $25 \%$.

-To allow educational organizations and those interested of family literacy to be better acknowledged to design, plan, develop, and implement family literacy programs to address the needs of family literacy for new comers and immigrant families. 
-To contribute to the efforts of community by making the participants feel they are an important part of the project.

Finally, to help me judge the clarity of my developed program, I ask myself these questions:

1-Is there a relationship between the objectives, ideas and needs that have been identified as priority areas?

2-Are the objectives practical and achievable?

3-Do the objectives focus on the critical part of the program?

\section{V- Designing Instructions}

In designing instructions, Caffarella \& Daffron (2013) describe the process as "designing the interaction between learners and instructors and/or learners and resource materials for each education and training activity" (p. 181). This component is involving four sections, including the development of learning objectives, selecting and organizing the content, choosing the instructional techniques and resources, and conducting instructional assessment (Caffarella \& Daffron, 2013). Caffarella \& Daffron state that the planner must carefully define learning activities for the educational session that support the objectives of the larger training program and that will achieve the desired learning outcomes. The goal of designing plans is to create a roadmap that planner can easily follow during applying the program. For me, I recognize it as a multi-step process, from identifying learning objectives to choosing instructional techniques. The 
learning objectives are described as what participants will learn as a result of their experience. Since the main focus of my workshop is to provide learners with enough experience in their areas of literacy needs, the learning objectives should be corresponded with improving the learners to "develop confidence in their skills to teach and foster early literacy skills". My workshop learning objectives should include a statement of who (the trainees), how (the training activities), and what (the literacy content), with some description of the activities that will be done to meet the needs (Appendix A). I plan some steps regarding learning techniques. For example, one step will be to hold different meetings with my advisor (manager) to discuss issues and learning progress. The instructional techniques will match the focus of the proposed learning outcomes, that I will use, and that I will take into account the backgrounds and experiences of the learners and the learning context. Parents are supposed to share in the workshop that focuses on the strengths of their culture and the importance of respecting other cultures. They will learn techniques to share their culture with their children, such as storytelling or talking about their traditional foods and mealtime in their home country.

The most important part of designing my instructional plan is to make evaluation of the instructional event one of its components. My instructional assessment will occur before, during, and after the event. An assessment tool will be used in the assessment of the trained parents' learning progress in the program, will also be used by them to recount and reflect on their experience.

To sum up, the plan will help me focus on my responsibilities to communicate with my learners in an effective way. These techniques would help me and all the members to evaluate the outcomes of the program, help in assessing what participants have learned or still need to practice, provide directions for learners to help them organize their own learning, and make suggestions for improving the program. 


\section{VI- Devising Transfer of Learning}

Devising transfer of learning is necessary for my program planning because it helps me to ensure that my participants are rally able to apply what they learned in the program. It is the ability to take what was learned in a program and apply it in real life that makes the program worth the time and the effort. This is important, because the learners have invested their time and energy in learning, and expect to see some positive outcomes. Caffarella \& Daffron (2013) state " Adult educators need to ask two further questions: did the learners actually learn what was intended, and will they be able to apply the new information in their personal work, or public lives?" (p. 210). Program planners should have knowledge about the major factors that influence transfer of learning. Caffarella \& Daffron (2013) suggest that planners can help to facilitate learning transfer by knowing the context within which the learner's will be expected to use what they learn, and by incorporating transfer strategies into the program plans for implementation before, during, and after the training program.

How to develop Transfer of Learning before the workshop experience:

1. As a program planner, I will work with the supervisors and some literacy educators to help identify individuals (immigrant parents) who are most likely to be successful in the training workshop.

2. Chosen trainees will be interviewed to determine their current level of English literacy, language needs, as well as motivation to learn and perceived interest in the program.

\section{Stakeholders will complete a survey of understanding with the workshop outlining learning goals and objectives for the experience.}


4. All members would have input on objectives and goals, offering suggestions and tasks analysis.

5. Trained parents would assess the appropriateness of the suggested training workshop process based on their individual learning goals for the workshop.

How to develop Transfer of Learning during the workshop:

1. During observation, I will ensure with the supervisors that trainees are receiving valuable experience and meeting learning needs and objectives.

2. Parents will be encouraged to work with their children in and out the center to observe how the children are progressing. One of the facilitators will also work with the children, observing how children's learning could be supported.

3. The workshop should include a written reflection draft, such as portfolio or final reflection paper to help learners to understand what supposed to be learned.

How to develop Transfer of Learning after the workshop:

1. The workshop process must be evaluated to ensure the transfer of learning, through learners and supervisor reflections, surveys, and feedback.

2. Evaluation is also important to decide whether the workshop is effective or should be improved in the future.

Finally, negotiation, motivation, good workplace environment, and changing the content, skills, and beliefs, that are to be transferred is essential to the success of transfer of learning.

\section{VII- Formulating Program Evaluations Plans}

Caffarella \& Daffron (2013) define the evaluation as "a process used to determine whether the design and delivery of a program were effective and whether the proposed outcomes were met" (p. 233). Healy (2000) states that evaluation is the determination of the worth of a program. The heart of program evaluation is judging the value or worth of education and training programs (Caffarella \& Daffron, 2013). Evaluation is important for designing program to improve delivery, management, and evaluation of program activities while in progress and to respond to needs and ideas identified for future programs. Furthermore, evaluation helps to assess how the program context (political, economic, organizational) impacts program

$$
-\varepsilon \vee V-
$$


processes and outcomes. In developing the immigrants' literacy program, for example, I completed preliminary evaluations with trainees' surveys (see Appendix B), as well as the instructor evaluation (see Appendix C).

Both formal and informal evaluation techniques should be used to evaluate the implementation of a program and to determine if its required outcomes were realized.

Evaluation is a process used to show whether or not the program was effective in meeting the aspired objectives. According to Caffarella \& Daffron, evaluation is a "continuous process" (p.233). To evaluate a program effectively, a planner has to implement more than one assessment tool. Formative evaluation is done to improve or change a program while it is in progress while Summative evaluation focuses on the results or outcomes after the program is completed (Caffarella \& Daffron, 2013). The evaluation of my literacy workshop would be both formative and summative. Trainees will develop written learning objectives for their needs and experience before it begins. During the workshop, they will discuss informally their new experience and whether their learning objectives are being successfully met. At the end of the workshop, both trainees and supervisors will be asked to submit a written evaluation of the success of the workshop. I recognize that making the most of evaluation opportunities while the program is in progress may allow me to correct missteps or alter the direction, based on trainees' reactions and feedback. I plan to make use of observation, interviews, portfolios, written questionnaires, and selfassessment, since trainees will be asked to reflect on what worked and what didn't work in the program and to offer suggestions for enhancement.

\section{Conclusion}

In order for program planners to be able to negotiate their program successfully, they should have a guide or model to follow. Thus, Caffarella's (2013) Interactive Model of Program Planning is a guide which seems particularly user-friendly for a beginner planner like me. I have learned from The Program Planning in Adult Education course that program planning for an adults "is like swimming in the ocean" (Caffarella \& Daffron, 2013, pg. 1) and

$$
-\varepsilon \vee \wedge-
$$


that a program planner must have the ability to skillfully dive in the depth of that ocean. As a program planner, I look beyond the learners who are directly involved with the program and whose voices need to be heard. This course taught me that it is necessary to connect the expectations (needs assessments) and outcomes (evaluations), to develop goals and objectives, and to identify ideas. To conclude, I found the Program Planning in Adult Education course very useful and using a model such as Caffarella's Interactive Model of Program Planning is the best way to be a successful program planner. 
Appendix A

Learning Objectives and Activities to Meet the Objectives

\begin{tabular}{|l|l|}
\hline Learning Objectives & Activities to Meet the Objectives \\
\hline $\begin{array}{l}\text { 1. Helping Child Learn how to Read, Spell and } \\
\text { Write in English }\end{array}$ & $\begin{array}{l}\text { - Demonstrate how children } \\
\text { learn language } \\
\text { promoting language } \\
\text { - Learn how to apply these } \\
\text { strategies }\end{array}$ \\
\hline 2.English Language Learning for both parents and \\
kids & $\begin{array}{l}\text { Understand the importance of } \\
\text { parents' talking to child and } \\
\text { having fun with language } \\
\bullet \text { Identify ways to encourage } \\
\text { learning language with child } \\
\text { through daily routines and } \\
\text { interaction }\end{array}$ \\
\hline 3. Reading and Story Books together & \\
\hline
\end{tabular}




\begin{tabular}{|c|c|}
\hline & $\begin{array}{l}\text { for both } \\
\text { - Explore ways parents can } \\
\text { support reading } \\
\text { - Participate in story telling activities } \\
\text { - Explore how reading aloud helps them learn to } \\
\text { read } \\
\text { - Visit a library weekly }\end{array}$ \\
\hline 4. Learning Two Languages & $\begin{array}{l}\text { - State the benefits of learning two languages } \\
\text { - Learn when it is the best time to learn a second } \\
\text { language } \\
\text { - Identify strategies that support learning } \\
\text { English Language with kid's first language at } \\
\text { home and school }\end{array}$ \\
\hline $\begin{array}{l}\text { 5. Listening, Speaking, Reading and } \\
\text { Writing Experiences in English }\end{array}$ & $\begin{array}{l}\text { - Recognize the relationship of listening, speaking, } \\
\text { reading and writing } \\
\text { - Identify how they can be supported through } \\
\text { every day activities }\end{array}$ \\
\hline
\end{tabular}




\section{Hunt club Community Center}

\section{An English Language and Literacy Workshop for Parents}

*Please circle the rating of your choice, or complete the question with a short answer.5 = Highest/Best/Most agree rating

$1=$ Lowest $/$ Worst/Least agree rating

1. Do you feel more confident about how you will handle an interaction with your kids when using a specific reading strategy? 54321

2. Was the role-playing in this course helpful to enhance your own English literacy?

54321

3. Do you feel that you will be able to provide better service to your child' literacy as a result of what you have learned in this class?

54321

$$
-\varepsilon \wedge r-
$$


4. Do you plan to practice what you have learned on your own with the materials provided by this course?

54321

5. What were the most and least helpful parts of the course?

6. Would you be interested in continuing to another literacy workshop? Explain

7. Is there any other training you feel would enhance your ability to better learn and teach the literacy? 
Appendix C

8. Class preparation

54321

7. Teaching skills

54321

8. Enthusiasm for subject

54321

9. Knowledge of subject matter 54321

10. Willingness to help trainees or further discuss material

54321

11. Relative to your knowledge at the beginning of this workshop, how would you rate the learning achieved in this course?

54321

$-\varepsilon \wedge \varepsilon-$ 
WOULD YOU RECOMMEND THIS WORKSHOP TO OTHERS?

YES NO

We value your opinion! Please share your comments and suggestions. 


\section{References:}

Alfred, M. \& Obamehinti, F. (2013). Perception of Family Literacy Among Immigrant Families. Journal of Texas School Women Executives, 2 (1), pp.16-29

Anderson, J., \& Morrison, F. (2007). “A great program... for me as a Gramma": Caregivers Evaluate a Family Literacy Initiative. Canadian Journal of Education, 30, pp. 68-89.

Caffarella, R. S. (2001). Developing Effective Learning Programs for Adults. Australian Council for Educational Research, 1 (1), pp. 1- 15

Caffarella, R. S. (2002). Planning programs for adults: A comprehensive guide (2nd ed.). San Francisco: Jossey-Bass.

Caffarella, R.S. \& Daffron, S. R. (2013). Planning programs for adult learners: A practical guide (3rd ed.) San Francisco: Jossey-Bass.

Cervero, R. M. and Wilson, A. L. (1996). Paying Attention to the People Work When Planning Educational Programs for Adults. In R. M. Cervero and A. L. Wilson (Eds.), What really matters in adult education program planning: Lessons in negotiating power and interests (pp. 5-13). San Francisco, CA: Jossey-Bass.

Cervero, R., \& Wilson, A. (2001). Power in practice: Adult education and the struggle for knowledge and power in society. San Francisco, CA: Jossey Bass Publishers.

Darling, S., \& Westbury, I. (2004). Parent Involvement in Children's Acquisition of Reading. The Reading Teacher, 57(8), pp.774-776

Forester, J. (1989). Planning in the face of power. Berkeley, CA: University of California. 
Garcia, D. C. \& Hasson, D. J. (N.D). Implementing Family Literacy Programs for Linguistically and Culturally Diverse Populations: Key Elements to Consider. The School Community Journal, pp.113-137

Healy, M. A. (2000). Knowing What Works: Program Evaluation. New Directions for Student Services, 90, pp. 57-65. doi: 10.1002/ss.9005

Kaestle, C. F., Damon-Moore, H., Stedman, L.C., Tinsley, K. \& Trollinger, Jr., W.V. (1991). Literacy in the United States. New Haven, CT: Yale University Press.

Neitzel. D. K (2006). How to Develop an Effective Training Program. IEEE Industry Applica Magazine, 18 (6) pp. 39-48

Sandmann, L.R., Kiely, R.C., Grenier, R.S., ( Spring 2009). Program Planning: The neglected dimension of service-learning, Michigan Journal of Community Service Learning, 15(2), pp17-33

retrieved from www.web.ebscohost.com.ezproxy.royalroads.ca

Smith, P. L., \& Ragan, T. J. (2005). Instructional design (3rd ed.). Hoboken, NJ: Wiley.

Sork, T.J., (1998). Program Priorities, Purposes, and Objectives. In P.S. Cookson

(Ed.), Program planning for the training and continuing education of adults:

North American perspectives, pp. 273-300

Sork,T.J., (2010). Planning and Delivering Programs, Handbook of Adult and Continuing Education. Sage Publications, CA 
$-\leqslant \wedge \wedge-$ 